\title{
“It's Pre-Service Teacher's Time”: Shifting the Focus of Communication Apprehension (CA) Research
}

\author{
Danang Tandyonomanu \\ Universitas Negeri Surabaya \\ Surabaya, Indonesia \\ danangtandyonomanu@unesa.ac.id
}

\author{
Tsuroyya \\ Universitas Negeri Surabaya \\ Surabaya Indonesia \\ tsuroyya@unesa.ac.id
}

\author{
Damajanti Kusuma Dewi \\ Universitas Negeri Surabaya \\ Surabaya, Indonesia \\ damajantikusuma@unesa.ac.id
}

\begin{abstract}
Anxiety to communicate in front of public is significantly associated with how individuals cope with and adjust to the stress of apprehension. Studies across multiple disciplines have investigated connections among Communication Apprehension (CA), instructional communication (e.g. language and various discipline applications), coping strategies (e.g. computer-mediated communication features), and psychological behaviors (e.g. introvert and extrovert traits). However, there has not been yet a systematic review of this discourse to date. This study explored 23 research articles and summarized how $\mathrm{CA}$ and coping tend to focus much on students and little to teachers, particularly pre-service ones. The exposure on students includes CA profile, demographics, causes, and remedy approaches. Communication scholars contribute to innovation of reducing $\mathrm{CA}$ level using computer-mediated communication. Yet, face-to-face interactions might potentially decrease pre-service teacher's CA level taking into account his cultural background and power which he would exercise to boost his confidence. Further research on this particular topic is worth investigating in the future.
\end{abstract}

Keywords-communication apprehension; instructional communication; language

\section{INTRODUCTION}

A large and ever growing body of literature demonstrates that Communication Apprehension (CA) is fundamental to instructional communication [1]-[5] including in the discipline of language teaching [6]-[9] and those of business [10], maritime [11], and nursing education [12]. There is also a clear evidence indicating that $\mathrm{CA}$ is strongly associated with how people cope with anxiety to communicate in front of public. Various dimensions of individuals' CAs have been linked to psychological outcomes including introversion and extroversion, individualism/ collectivism, and acceptance/ denial [13]-[16].
The fact that psychological outcomes of coping with CA are highly consequential becomes further apparent upon examining such as identity and more private aspect, i.e. religion. The former entails individuals who originated from a minor ethnic group may experience CA twice as much as the dominant ones. Within the country of Singapore, Malay immigrants for instance prove to have higher CA than Chinese-born Singaporeans [17]. However, the latter claims an intriguing argument calling a religion, a private human aspect, also intervenes individual's CA level. In France, Catholics incline to encounter lower CA than Muslims. What is more, Catholics show higher level of Willingness to Communicate (WTC) and Self-Perceived Communication Competence (SPCC) [12].

CA scholars have been contributing to research on coping in a number of valuable ways including identifying traditional communication patterns [1], [2], [6], [7], [12] and communication technology innovations [17]-[20] that help or hinder student's psychological adjustments. As we have noted elsewhere, much of literature assumes that coping includes communicative behaviors such as receiving teacher confirmation, being adaptive and prepared prior to oral presentations, switching codes, avoiding certain topics, and abandoning messages [5], [8], [9]. The crucial role that communicative behaviors plays in adjusting to CA suggests several potential opportunities for interventions including communication technology [17]-[20] that are poised to become increasingly important as the digital turn grows and computermediated communication improves [21]-[25]. However, the precise connections between $\mathrm{CA}$ and coping with pre-service teachers remain somewhat vague and unsubstantiated [26], leaving many questions about their implications for practice. Despite abundant studies on coping with CA, they are inadequate to build effective theoretical understanding that yields improvement on the remedy of pre-service teacher's CA. This is partly because of overexposure focus on students and in- 
service teachers as the research participants [1], [2], [27], [4], [5], [7]-[12].

This literary review aims to provide structure to the scholarly literature by examining published studies on coping CA that include communication interventions from students and teachers. This study sought to critically evaluate the nature of CA of how individuals cope with CA. The primary objectives of this study were identifying underlying conceptual and theoretical principles that were recommended for interventions and educational practice, and suggesting future research direction on coping with pre-service teacher's CA.

\section{METHODS}

A rational approach to tackle the research question was first to obtain qualitative data consisting of 23 research articles on $\mathrm{CA}$ and communication education from the earlier years to the present day. This subsequently led to the next step of assessing CA context, to understand why CA was being used in a particular way, and what implications this had.

The first dataset obtained was CA implementation in the field of pedagogy including instructional and educational communication. Scholars posed arguments of student's CA profile such as causes, plausibility of its relationship with educational traits and demographic aspects, and strategies to remedy CA.

The next dataset obtained was the overarching exposure of $\mathrm{CA}$ in language teaching research explored from both external and internal aspects to reduce student's CA. The former argued providing situated learning environment and offering teacher's full attention served as significant CA treatment. The latter however, discussed the importance of improved student's preparation prior to public speaking activity and frequent training of language learning methods.

The last was CA contribution in the field of communication science. Computer-Mediated Communication (CMC) scholars focused their investigation on whether different nature of CA exist within $\mathrm{CMC}$ area incorporating nonverbal features to match face to face interaction context. On the other hand, intercultural communication researchers highlighted the centrality of identity and culture as a determinant factor of CA level.

\section{RESULTS AND DISCUSSION}

This section is divided into three main subsections. In order to identify the underlying conceptual and theoretical practice of CA deemed to be recommendation for intervention and educational practice, we assessed CA research based on two broad disciplines, i.e. education and communication. In addition, the assessment would provide a better understanding of CA nature and coping in the classroom context. The second subsection explained further coping with CA from communication perspective. This however would support the idea of CA intervention which was the main focus of this study. Lastly, we suggested an agenda for advancing research in the future focusing on coping with pre-service teacher's CA.

\section{A. Within Instructional and Language Dimensions}

The historical use of CA in education research originated from the claim of placing communication as central role in teacher education [6]. US government welcomed this claim judging that communication skill was mandatory for students by including this expertise in K12 and American colleges. The discipline of communication education therefore played an important role in developing sciences and practical skills [28].The research trend then shifted to explorations of communication topics such as Public Speaking Anxiety (PSA) and CA both at school and higher education levels [5], [16].

Instructional communication, a more specific area of communication education research, began to rigorously examine CA with its complexity within the classroom context. Several studies centered around causes of CA which addressed external and internal factors. The former showed a larger proportion that than the latter with audience response as the highest percentage. Internal factors including unpreparedness and inadequate speaking skills, however remained unsubstantial [29]. Research also identified self-critical and social assessing self-talk as factors causing individuals to experience high CA and PSA [30]. Finally, understanding the causes of CA comprehensively will contribute to the development of CA management for educational practice.

In relations to the causes of $\mathrm{CA}$, scholars suggested several strategies to manage student's CA. Among others were increasing the frequency of public speaking practice and perceiving negative assessment as motivation for students to be able to lower their CA [11]. Teachers however offered distinct coping method such as conducting three key teacher confirmation activities that would support student's CA management. The activities included giving verbal and nonverbal responses, fully attending student's learning process, and organizing the classroom with various teaching methods [5]. In addition to teacher confirmation, providing student's preference of environment during the classroom interaction would allow students to remedy their anxiety [7]. These strategies however require particular adjustments by taking educational and personality traits into account.

The next prominent discussion of CA was its nature that was linked to any plausible relationship with both educational and personality traits. Learning styles, ambiguity, tolerance, learning achievement, and seating preferences were educational traits which proved to be prevalent to student's CA level [10], [28]. The relationship between CA level and similar traits such as passive classroom participation and low learning motivation existed, thus teachers should develop a comprehensive measurement to assess CA during teacher-student interactions [2]. Although these traits affect CA level significantly, we argue that investigation on these cannot be separated from examining student's cultural aspect.

Personality traits on the other hand were examined using psychological perspective. Spitzberg argued high CA level was associated with extreme lonely individuals. A lower CA figure was shown for situational lonely students at UCLA. This finding then contributed to the development of therapeutic model for high CA individuals [13]. In addition to lonely individuals, CA was identical to shyness, minor ethnic group and/ or religion. 
Shy students tended to experience extreme apprehension in the same manner as Malaysian immigrants in Singapore or Muslim non-Caucasian in France [14], [15], [20]. This reinforces the previous claim stating that $\mathrm{CA}$ research must be inclusive with the involvement of cultural background.

The trend of CA research extended to language discipline in such a way that linguistic and broad cultural aspects were thoroughly investigated. Within the language dimension, CA was associated with inadequate speaking skills due to limited vocabulary [11], thus CA and language learning were interrelated and had become overarching discussion. In fact, CA was indicated as a major constraint in language learning [8]. The aspect of cultures within Teaching English for Speakers of Other Languages (TESOL) scholarships was examined with a focus on how to provide comfortable setting for learners to speak without anxiety.

\section{B. Towards CMC Innovations}

To mediate individuals with $\mathrm{CA}$ management, CMC scholars sought to provide a better strategy to cope with student's CA. Snapchat, a media message application, had become a useful tool in overcoming high CA level. Apart from its entertainment purpose, Snapchat offered a unique characteristic that helped persons with high CA level solve their communication constraint [19]. A similar study on Second Life, an application allowing individuals to have a totally different personality, found that shy Second Life users rarely experienced CA even though this was inconsistent with an increase of their confidence level. This was partly because Second Life lacked of visual and audio cues [20].

Another perspective on the applicability of CMC to coping with CA proposed a specific tool called voice over that lowered high CA to moderate levels. What's more, this tool could increase student's intercultural awareness in learning foreign languages [17]. CMC resolved this intercultural aspect by providing various emoji serving as nonverbal messages which conveyed emotion and feelings. Previous studies argued emoji usage successfully delivered the intended meaning of MMA users and increased social connectedness and emotional bonds [22][31], [32]. In the end, the emphasis of CMC strategy in coping with $\mathrm{CA}$ rests on transforming cultures into nonverbal features that can best moderate CA level.

\section{Beyond Student's Perspective}

Much of CA literature in the field of instructional communication and education focused on students and inservice teachers. The former examined student anxiety in communicating in front of public including experiences, causes, and resolutions [1], [4],[9],[11], [12]. The latter discussed the importance of developing a teacher measurement scale to better assess student's CA [2]. There has been little discussion on preservice teachers particularly on their CA profile. The existing literature with regards to pre-service teachers focused on the impact of their failure in teaching practicum towards teacher associates, faculty members, and the quality of professional program in general [26]. In addition, similar literature investigated the profile of in-service teachers in Nigeria and claimed that age and gender proved to be non-determinant factors towards their CA [3].
Further research on pre-service teachers would serve as a potential alternative to better understand a dynamic classroom interaction. Profiles of their CA, self-perceived communication competence, and willingness to listen would affect greatly on how their student manages his CA assuming that teacher's confirmation helps remedy student's CA [5]. What is more, a face-to-face interaction would enable both pre-service teachers and students to exercise more power which might boost their level of confidence leading to lower their CA level [18] [20].

\section{CONCLUSION}

This study highlights an on-going trend of CA research with respect to pedagogy and education disciplines including profile of student's CA, demographics, causes, and methods of reducing $\mathrm{CA}$ level. On the other hand, CA research also focuses the relationship between $\mathrm{CA}$ and cultures as well as innovations provided by CMC. This study claims that cultural aspects potentially affect either student, or teacher to experience and to remedy his CA. Providing that there is abundant CA literature focusing on students and in-service teachers, we argue that it is necessary to shift the emphasis to pre-service teachers with an aim to better understand the classroom interaction in more engaging ways.

\section{REFERENCES}

[1] C. C. Malachowski and M. M. Martin, "Instructors' perceptions of teaching behaviors, communication apprehension, and student nonverbal responsiveness in the classroom," Commun. Res. Reports, vol. 28, no. 2, pp. 141-150, 2011

[2] A. E. Gümüș and A. K. Geçer, "Developing a scale for communication apprehension with lecturers," Eurasian J. Educ. Res., no. 31, pp. 55-74, 2008.

[3] E. Oladipo, O. Agbajeola, and A. Adenaike, "Assessing Communication Apprehension Among In-Service Teachers in A University of Education,' Res. Humanit. Soc. Sci., vol. 2, no. 7, pp. 27-32, 2012.

[4] F. Amiri and M. Puteh, "Oral Communication Apprehension among International Doctoral Students," English Lang. Teach., vol. 11, no. 2, pp. $164-171,2018$

[5] M. Khamis and N. Rashdi, "The Relationship of Teachers' Confirming Behavior towards Students' Communication Apprehension in Malaysian Private Secondary Schools," Acad. J., vol. 6, no. 2, pp. 171-182, 2017.

[6] S. KAVANOZ, “an Explanatory Mixed Method Study on Pre-Service Language Teachers' Communication Apprehension Towards Their Instructors," Int. J. Lang. Teach., vol. 5, no. 1, pp. 631-650, 2017.

[7] M. Rahmatollahi and G. F. Khalili, "Relationship between intermediate EFL learners' communication apprehension, willingness to communicate, and speaking ability," Int. J. Appl. Linguist. English Lit., vol. 4, no. 6, pp. 23-32, 2015.

[8] M. B. Rafek, N. H. L. B. Ramli, H. B. Iksan, N. M. Harith, and A. I. B. C Abas, "Gender and Language: Communication Apprehension in Second Language Learning," Procedia - Soc. Behav. Sci., vol. 123, pp. 90-96, 2014

[9] N. I. Tiono and A. Sylvia, "the Types of Communication Strategies Used By Speaking Class Students With Different Communication Apprehension Levels in English Department of Petra Christian University, Surabaya," Kata, vol. 6, no. 1, pp. 30-46, 2004.

[10] J. L. Arquero, C. Fernández-Polvillo, T. Hassall, and J. Joyce, "Relationships between communication apprehension, ambiguity tolerance and learning styles in accounting students," Spanish Account. Rev., vol. 20, no. 1, pp. 13-24, 2015.

[11] N. Aeni, B. Jabu, M. A. Rahman, and J. E. Strid, "English Oral Communication Apprehension in Students of Indonesian Maritime," Int. J. English Linguist., vol. 7, no. 4, pp. 158-165, 2017. 
[12] J. Emory, T. Kippenbrock, P. Lee, M. T. Miller, and J. Reimers, "Communication apprehension and willingness to listen in nursing education," J. Prof. Nurs., vol. 34, no. 4, pp. 1-5, 2017.

[13] B. Spitzberg, "Loneliness and Communication Apprehension," in The Western Speech Communication Association Convention, 1981, pp. 1-32.

[14] S. M. Croucher, "Communication Apprehension, Self-Perceived Communication Competence, and Willingness to Communicate: A French Analysis," J. Int. Intercult. Commun., vol. 6, no. 4, pp. 298-316, 2013.

[15] S. Croucher, D. Rahmani, K. Sakkinen, and D. Hample, "Communication Apprehension, Self Perceived Communication Competence, and Willingness to Communicate in Singapore," J. Intercult. Commun., no. 40, 2016.

[16] A. K. Geçer and A. E. Gümüş, "Prediction of public and private university students' communication apprehension with lecturers," Procedia - Soc. Behav. Sci., vol. 2, no. 2, pp. 3008-3014, 2010.

[17] S. A. Çapan, "An online alternative to alleviate communication apprehension,” Int. J. Appl. Linguist. English Lit., vol. 2, no. 3, pp. 202 210, 2013.

[18] N. M. Punyanunt-carter, J. J. J. Delacruz, and J. S. Wrench, "Investigating the Relationships Among College Students' Satisfaction, Addiction, Needs, Communication Apprehension, Motives, and Uses \& Gratifications with Snapchat," Comput. Human Behav., pp. 1-28, 2017.

[19] N. M. Punyanunt-Carter, J. J. D. La Cruz, and J. S. Wrench, "Analyzing College Students' Social Media Communication Apprehension,' Cyberpsychology, Behav. Soc. Netw., vol. 21, no. 8, pp. 511-515, 2018.

[20] J. K. Hammick and M. J. Lee, "Do shy people feel less communication apprehension online? the effects of virtual reality on the relationship between personality characteristics and communication outcomes," Comput. Human Behav., vol. 33, pp. 1-9, 2013.

[21] D. Cernea and A. Kerren, "A survey of technologies on the rise for emotion-enhanced interaction," J. Vis. Lang. Comput., vol. 31, pp. 70-86, 2015.

[22] V. Garrido, “A Frown Emoji Can Be Worth a Thousand Words: Perceptions of Emoji Use in Text Messages Exchanged Between Romantic Partners," Telemat. Informatics, 2017.
[23] R. Grieve, "Computers in Human Behavior Unpacking the characteristics of Snapchat users : A preliminary investigation and an agenda for future research," Comput. Human Behav., vol. 74, pp. 130-138, 2017.

[24] S. Holtzman, D. Declerck, K. Turcotte, D. Lisi, and M. Woodworth, "Emotional support during times of stress: Can text messaging compete with in-person interactions?," Comput. Human Behav., 2017.

[25] K. Kafetsios, D. Chatzakou, N. Tsigilis, and A. Vakali, "Experience of emotion in face to face and computer-mediated social interactions: An event sampling study," Comput. Human Behav., vol. 76, pp. 287-293, 2017.

[26] P. J. Danyluk, F. Luhanga, Y. N. Gwekwerere, L. MacEwan, and S. Larocque, "Failure to Fail in a Final Pre-service Teaching Practicum," Can. J. Scholarsh. Teach. Learn., vol. 6, no. 3, pp. 1-17, 2015.

[27] T. Batista and A. Johnson, "The Children's Aid Society," J. Fam. Hist., vol. 42, no. 1, pp. 67-80, 2017.

[28] S. P. Morreale, J. M. Valenzano, and J. A. Bauer, "Why communication education is important: a third study on the centrality of the discipline's content and pedagogy," Commun. Educ., vol. 66, no. 4, pp. 1-21, 2016.

[29] L. LeFebvre, L. E. LeFebvre, and M. Allen, "Training the butterflies to fly in formation: cataloguing student fears about public speaking," Commun. Educ., vol. 67, no. 3, pp. 348-362, 2018.

[30] X. Shi, T. M. Brinthaupt, and M. McCree, "The relationship of self-talk frequency to communication apprehension and public speaking anxiety," Pers. Individ. Dif., vol. 75, pp. 125-129, 2015.

[31] D. Tandyonomanu and Tsuroyya, "Emoji: Representations of Nonverbal Symbols in Communication Technology," IOP Conf. Ser. Mater. Sci. Eng., vol. 288, no. 1, pp. 0-7, 2018.

[32] S. H. Hsieh and T. H. Tseng, "Computers in Human Behavior Playfulness in mobile instant messaging : Examining the in fl uence of emoticons and text messaging on social interaction," Comput. Human Behav., vol. 69, pp. 405-414, 2017. 